\title{
Association between cardiovascular risk- factors and venous thromboembolism in a large longitudinal study of French women
}

\author{
C. J. MacDonald ${ }^{1,2}$, A. L. Madika ${ }^{1,2,3}$, M. Lajous ${ }^{4,5}$, M. Canonico ${ }^{1,2}$, A. Fournier ${ }^{1,2}$ and M. C. Boutron-Ruault ${ }^{12^{*}}$ (D)
}

\begin{abstract}
Background: Previous studies have shown conflicting results regarding the influence of cardiovascular risk-factors on venous thromboembolism. This study aimed to determine if these risk-factors, i.e. physical activity, smoking, hypertension, dyslipidaemia, and diabetes, were associated with the risk of venous thromboembolism, and to determine if these associations were confounded by BMI.
\end{abstract}

Methods: We used data from the E3N cohort study, a French prospective population-based study initiated in 1990, consisting of 98,995 women born between 1925 and 1950. From the women in the study we included those who did not have prevalent arterial disease or venous thromboembolism at baseline; thus 91,707 women were included in the study. Venous thromboembolism cases were self-reported during follow-up, and verified via specific mailings to medical practitioners or via drug reimbursements for anti-thrombotic medications. Hypertension, diabetes and dyslipidaemia were self-reported validated against drug reimbursements or specific questionnaires. Physical activity, and smoking were based on self-reports. Cox-models, adjusted for BMI and other potential risk-factors were used to determine hazard ratios for incident venous thromboembolism.

Results: During 1,897,960 person-years (PY), 1, 649 first incident episodes of thrombosis were identified at an incidence rate of 0.9 per 1000 PY. This included 505 cases of pulmonary embolism and 1144 cases of deep vein thrombosis with no evidence of pulmonary embolism. Hypertension, dyslipidaemia, diabetes, smoking and physical activity were not associated with the overall risk of thrombosis after adjustment for BMI.

Conclusions: Traditional cardiovascular risk factors were not associated with the risk of venous thromboembolism after adjustment for BMI. Hypertension, dyslipidaemia and diabetes may not be risk-factors for venous thromboembolism.

Keywords: Venous thromboembolism, Pulmonary embolism, Epidemiology, Prospective study

\footnotetext{
* Correspondence: marie-christine.boutron@gustaveroussy.fr

'INSERM (Institut National de la Santé et de la Recherche Médicale) U1018, Center for Research in Epidemiology and Population Health (CESP), Institut Gustave Roussy, Villejuif, France

${ }^{2}$ Université Paris-Saclay, Université Paris-Sud, Villejuif, France

Full list of author information is available at the end of the article
}

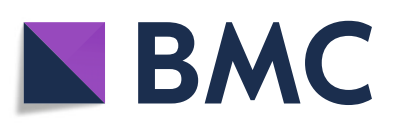

(- The Author(s). 2021 Open Access This article is licensed under a Creative Commons Attribution 4.0 International License, which permits use, sharing, adaptation, distribution and reproduction in any medium or format, as long as you give appropriate credit to the original author(s) and the source, provide a link to the Creative Commons licence, and indicate if changes were made. The images or other third party material in this article are included in the article's Creative Commons licence, unless indicated otherwise in a credit line to the material. If material is not included in the article's Creative Commons licence and your intended use is not permitted by statutory regulation or exceeds the permitted use, you will need to obtain permission directly from the copyright holder. To view a copy of this licence, visit http://creativecommons.org/licenses/by/4.0/ The Creative Commons Public Domain Dedication waiver (http://creativecommons.org/publicdomain/zero/1.0/) applies to the data made available in this article, unless otherwise stated in a credit line to the data. 


\section{Introduction}

Venous thromboembolism (VTE) is a multifactorial condition resulting from the formation of blood clots in the deep veins (deep vein thrombosis, DVT), or their migration to the lungs (pulmonary embolism, PE). Mortality rate estimates for the European Union give 500,000 VTE-related deaths per year [1]. VTE is considered a major global health burden, and a leading cause of lost disability-adjusted life years [2]. Established risk factors for VTE include long hospitalisations, surgery [3], and cancers [4]. Family history of VTE, non-O blood groups, and treatments such as menopausal hormone therapy (MHT) also increase the risk of VTE [5].

It is currently poorly understood how cardiovascular risk-factors contribute to VTE risk. Many common cardiovascular risk factors have been associated with VTE in meta-analyses including obesity, type 2 diabetes, smoking, non-O blood group, and high triglyceride concentrations [6, 7]. However, these associations are heterogeneous between studies $[8,9]$. For example a recent cross-sectional study observed a positive association between hypertension and VTE [10]. However, a metaanalysis found that blood pressure was inversely associated with the risk of VTE [11], and a prospective study utilising time-varying covariates found no association [12]. Previous studies have failed to account for female specific risk-factors for VTE, such as parity, and the use of MHT [9]. As BMI is a major risk-factor for many of these conditions, it is possible that previous estimates not accounting for BMI are biased, and that common CVD risk-factors are not directly associated with the risk of VTE.

In this work, we aimed to explore the relationship between cardiovascular risk factors and VTE, in a large prospective study of middle-age, and older women controlling for specific female risk-factors for VTE. The hypothesis was that any associations between arterial risk-factors and VTE were confounded by BMI.

\section{Methods}

\section{Study cohort}

The E3N (Etude Epidémiologique auprès de femmes de la Mutuelle Générale de l'Education Nationale (MGEN)) cohort study was set up in 1990, and included 98,995 women born 1925-1950 and affiliated to the MGEN, a health insurance plan for workers in the education system and their spouses. The objective was to identify risk factors for cancer and chronic conditions in women. In 1990, participants signed an informed consent form in accordance to the French National Commission for Data Protection and Privacy. Part of this study is the French component of the European Prospective Investigation into Cancer (EPIC) [13].
Participants were asked every 2-3 years to complete self-administered questionnaires to provide and update medical events and lifestyle (1990, 1992, 1993, 1995, 1997, 2000, 2002, 2005, 2008, and 2011). The baseline for the current study was the date the participants answered the 1992 questionnaire. Participants were excluded from this study if they had stroke, coronary heart disease, cancer, death $(n=6452)$, or VTE $(n=390)$ before 1992. We excluded 721 participants with no reported baseline body mass index (BMI). The final study population included 91,707 women.

\section{Assessment of venous thromboembolism cases}

Non-fatal incident VTE cases were identified from selfreports in the follow-up questionnaires sent to the study participants after baseline. Before the 2008 questionnaire, participants were asked to report VTE events (without distinguishing between deep and superficial VTE) as yes/no, and the corresponding date, or pulmonary embolism (PE) and the corresponding date. From 2008 on, questionnaires were specific for DVT or PE, asking participants not to report superficial VTE. A flow-chart of case identification is presented in the supplementary material (sup. Fig. 1). All cases were considered validated, either by imaging procedures, or by reimbursement for anti-thrombotic medications following the event.

When participants reported VTE or PE events in the 2005 or preceding questionnaires, they were contacted via another letter, whereby they were asked to provide medical documents relating to the event. In addition, a questionnaire including information on potential predisposing factors (including surgeries, immobilisation over 8 days, cancers, long voyages on airplanes, or other factors) for thrombosis and characteristics of the event was sent to the medical doctors who followed these participants, permitting classification of the events as primary or secondary. To be validated, clinical events had to be diagnosed using an imaging procedure. PE was defined as the presence of either a positive pulmonary angiography or a positive helicoidal computed tomography or a high-probability ventilation/perfusion lung scan. DVT had to be diagnosed by use of compression ultrasonography or venography.

For DVT/PE identified from the 2008 and 2011 questionnaires, we confirmed that cases were associated with a relevant antithrombotic prescription (Heparin, Tinzaparin, Fragmin, Fraxiparin, Enoxaparin, Acénocoumarol, Fluindione, Warfarin, Dabigatran, Rivaroxaban, or Apixaban) at least twice in the year following the VTE using the MGEN database. Self-reported cases that were not validated with anti-thrombotic medications were not considered as valid cases. We cross-referenced selfreported VTE with self-reported hospital admissions, to 
determine if there was any associated cancer, immobilisation, hospitalisation, surgery (e.g. hip and knee surgeries), or trauma, which would indicate a secondary VTE. All other cases were considered a primary event with no obvious cause.

Fatal cases were identified from national death registers using International Classification of Diseases (ICD) -9 (codes 4151 and 4539) and ICD-10 (codes I26.0 and I26.9).

Amongst the 91,711 participants in the study, 1443 incident first cases of VTE were identified during followup (1992-2005) as previously described [14], and a further 1277 identified from in 2008 and 2011. Cases of superficial and upper extremity VT $(n=848)$ and cases for which the type could not be determined $(n=223)$ were not considered. As a result, 1649 incident cases of VTE consisting of 505 cases of PE and 1144 cases of DVT with no evidence of PE were considered.

\section{Assessment of cardiovascular risk factors}

All cardiovascular risk factors considered were updated at each questionnaire cycle for this study.

During the study period, women were asked if they had received a diagnosis of hypertension that required treatment in all questionnaires. In 2004, a drug reimbursement database became available for women in the study. Previously we have observed an $82 \%$ positive predictive value/agreement from self-reports when cross correlating with the drug reimbursement database for antihypertensive medications. (Anatomical Therapeutic Chemical Classification System codes C02, C03, C07, C08, and C09).

Type-2 diabetes cases were based on self-reports, which were then validated through a specific questionnaire mailed to women having reported type- 2 diabetes, confirming either elevated glucose concentration at diagnosis (fasting $\geq 7.0 \mathrm{mmol} / \mathrm{l}$ or random glucose $\geq 11.1$ $\mathrm{mmol} / \mathrm{l})$, treatment with diabetes drugs, and/or fasting glucose or $\mathrm{HbA} 1 \mathrm{c} \geq 7 \%,(53.0 \mathrm{mmol} / \mathrm{mol})$, respectively [15]. Cases occurring after 2004 were identified using the MGEN reimbursement database. All women reimbursed for glucose lowering medications at least twice in a given year were classified as having type- 2 diabetes.

Dyslipidaemia was self-reported at baseline, and at all follow up questionnaires. Participants in the study were asked if they had received a diagnosis of abnormal cholesterol from their doctor, or if they required treatment to control their cholesterol. Participants who did not provide information on dyslipidaemia were classified as unknown. The use of lipid-lowering medications was accounted for from 2004 onwards, using the MGEN database. Prior to 2004, statin use was considered unknown. As a secondary analysis, due to potential effects of statins on VTE risk, we considered the combination of self-reported dyslipidaemia, as well as statin reimbursement as 'treated dyslipidaemia'. Separate classes were also created for 'reported dyslipidaemia and no statin reimbursement' and 'no reported dyslipidaemia and statin reimbursement'.

We assessed usual physical activity from questionnaires that included questions on the time spent walking (to work, shopping, and leisure time), cycling (to work, shopping, and leisure time), housework, and sports activities. Metabolic equivalents (METs) per week were estimated by multiplying the hourly average METs for each item based on values from the Compendium of Physical Activities [16] by the reported activity duration. Physical activity was split into three tertiles depending on the population distribution. Blood $\mathrm{ABO}$ group and smoking were based on self-reports, and at each questionnaire participants were classified as smoker, ex-smoker, or never smoker.

\section{Assessment of adjustment variables}

Self-reported height and weight were used to calculate body mass index (BMI), defined as weight $(\mathrm{kg})$ divided by squared height $\left(\mathrm{m}^{2}\right)$. In the cohort, self-reported anthropometry is considered reliable from a validation study [17].

Use of MHT was assessed using a booklet containing photos of all types of oestrogens and progestogens, as previously described [14]. Age at, and type of menopause was defined as either (in decreasing order of priority) age at last menstrual period, age at bilateral oophorectomy, self-reported age at menopause, age at start of MHT, or the age at the start of menopausal symptoms. If unavailable, the median age at menopause for the cohort (51 years for natural menopause, 47 years for artificial menopause) was imputed. Women were considered menopausal at baseline if any of these events occurred before the start of follow-up. Parity was based on selfreports. Family history of cardiovascular disease (stroke or coronary disease in either parent) was based on selfreports. Incident fractures, cancers, heart attacks, and strokes occurring during follow-up were based on cases validated by specific questionnaires to the women and their practitioners.

\section{Statistical analysis}

As risk-factor status can change over time, we updated values in modelling using information from follow-up questionnaires, similar to the method used by Wattanakit et at [12], i.e. the dataset contained multiple rows for each participant. If a participant reported hypertension, diabetes, or dyslipidaemia in one questionnaire, they were considered to have this condition for the remainder of follow-up. 
Outcomes considered were the first VTE, then the first PE, or DVT; and then models considered the status of the event, i.e. primary VTE, and secondary VTE. In order to account for competing events when considering the specific types of VTE, the other types of VTE were censored from the analysis at the time of the competing event.

Potential confounders were selected with the help of directed acyclic graphs (supplementary Fig. 2). Riskfactors were assessed one by one, (i.e. we did not mutually adjust for hypertension, diabetes and dyslipidaemia), using Cox proportional hazard models with age as the time-scale in order to account for the effect of age. Models were initially assessed with age as the time scale (model 1), then on statin use (yes/no), for education level (high-school/no high-school/university), parity (0, $1,>1$ ), menopausal status (yes/no), ever use of MHT (yes/no), type of menopause (natural/artificial) (model 2 ), and finally BMI (model 3). Models were not mutually adjusted for the considered risk factors, in order to reduce the likelihood of introducing collider bias. Time at entry was the age at the beginning of follow-up (i.e., the age when the participants answered the questionnaire sent out in 1992); exit time was the age when participants were diagnosed with VTE, died (dates of death were obtained from the participants' medical insurance records), were lost to follow-up, or reached the end of the follow-up period (December 31, 2011), whichever occurred first.

As VTE can be provoked by bone fractures, other cardiovascular diseases, or cancer, we also considered a model controlled for incident fractures (time dependent, yes/no), cancers (time dependent, yes/no), and both heart attack and stroke (time dependent, yes/no), during follow-up as sensitivity analysis. The next sensitivity analysis excluded cases occurring after 2005 that were not part of the mailing conducted to validate the VTE cases. Another sensitivity analysis mutually adjusted for comorbid conditions at baseline, i.e. when considering hypertension, diabetes and dyslipidaemia were adjusted on at baseline. Finally, in the case of associations which were unexpected or suspected to be due to bias, we considered models using only baseline variables to determine if this was due to the inclusion of collider variables during follow-up.

When considering blood-groups 7834 participants were excluded from this analysis due to missing data on blood group. As a hypothesis generating exercise, we wished to determine if the associations between these risk factors were consistent over blood-groups, which are a major risk-factor for VTE. As blood-group is a determinant of blood lipid levels [18], hypertension [19], diabetes [20], and coagulation factors including von Willibrand factor [21], we considered effect modification was plausible regarding dyslipidaemia, hypertension and diabetes.

Missing values (occurring in less than $5 \%$ of data) were imputed as the mean for continuous variables, and the median for categorical variables. During follow-up, if a value was missing, the previous value was imputed.

All statistical analyses were performed using $\mathrm{R}$ and $\mathrm{R}$ studio, with the 'Survival' package. A Bonferroni corrected $p$-value for statistical significance was 0.01 . The proportional hazards assumption was assessed using the cox.zph function in R. A p-value is generated for the Person product-moment correlation between the scaled Schoenfeld residual, and the time transformation for each variable [22].

\section{Results}

During 1,897,960 person-years (PY) (mean follow-up of 20.7 years), 1649 first incident episodes of VTE were identified at an incidence rate of 0.9 per 1000 PY.

Table 1 displays data at baseline, and after 10 years of follow-up. The cardiovascular risk profile of the study participants worsened during follow-up, although total physical activity increased. BMI increased during followup from a mean of $22.9 \mathrm{~kg} / \mathrm{m}^{2}$ to $23.8 \mathrm{~kg} / \mathrm{m}^{2}$. Hypertension prevalence increased from 35.2 to $44.4 \%$, diabetes from 1.0 to $2.2 \%$, and self-reported dyslipidaemia from 7.8 to $25.4 \%$. Smoking prevalence decreased during follow-up from 14.5 to $11.0 \%$. At 2004, approximately $25 \%$ of study participants had been reimbursed for statins.

In unadjusted models, hypertension was associated with an increased risk of VTE (HR ${ }_{\text {HTA }}=1.21$ (1.10: 1.34)), but this was not consistent after adjustment for BMI (HR ${ }_{\text {HTA }}=1.05$ (0.95: 1.16)). Current smokers were associated with a lower risk of VTE in unadjusted models, but this was not observed after adjustment for BMI (HR smokers $=0.87$ (0.73: 1.03)). Mean BMI among smokers at baseline was 22.5 (3.3) $\mathrm{kg} / \mathrm{m}^{2}$ compared to 22.9 (3.3) $\mathrm{kg} / \mathrm{m}^{2}$ among never smokers. Diabetes, dyslipidaemia, and physical activity were not associated with the risk of VTE in unadjusted or adjusted models (Table 2). Neither treated hypertension, nor treated dyslipidaemia were associated with the risk of VTE (not tabulated).

When considering VTE subtypes (Table 2), including PE, DVT, primary, and secondary VTE, hypertension showed a borderline positive association with $\mathrm{PE}$ $\left(\mathrm{HR}_{\mathrm{hta}}=1.20\right.$ (0.99: 1.45)) after adjustment for BMI, and was consistent when considering treated hypertension, but not untreated hypertension $\left(\mathrm{HR}_{\mathrm{hta}}\right.$ trt $=1.24(0.99$ : $1.56), \mathrm{HR}_{\text {hta }}$ untrt $\left.=1.16(0.93: 1.45)\right)$. An inverse association with the highest tertile of physical activity was observed for primary VTE $\left(\mathrm{HR}_{\mathrm{T} 3}=0.71(0.56: 0.90)\right)$ after adjustment for BMI. Dyslipidaemia was associated with 
Table 1 Participant demographics at the beginning of followup, and mid-way through the study period

\begin{tabular}{|c|c|c|}
\hline & $\begin{array}{l}\text { Status at } 1992 \\
(n=91,711)\end{array}$ & $\begin{array}{l}\text { Status at } 2002 \\
(n=88,302)\end{array}$ \\
\hline \multicolumn{3}{|l|}{ Dynamic variables } \\
\hline Age (years) & $51.1(6.6)$ & $61.4(6.6)$ \\
\hline Declared hypertension (\%) & 35.2 & 44.4 \\
\hline Treated hypertension (\%)* & Unknown & 26.7 \\
\hline Diabetes (\%) & 1.0 & 2.2 \\
\hline Declared dyslipidaemia (\%) & 7.8 & 25.4 \\
\hline Statin user $(\%)^{*}$ & Unknown & 25.1 \\
\hline Treated dyslipidaemia $(\%)^{*}$ & Unknown & 12.9 \\
\hline $\mathrm{BMI}\left(\mathrm{kg} / \mathrm{m}^{2}\right)$ & $22.9(3.3)$ & $23.8(3.8)$ \\
\hline $\mathrm{BMI}<18.5(\%)$ & 4.0 & 3.9 \\
\hline $18.5-24.9(\%)$ & 75.8 & 68.7 \\
\hline 25.0-30.0 (\%) & 16.4 & 21.6 \\
\hline > $30.0(\%)$ & 3.8 & 5.8 \\
\hline Physical activity (METs) & $51.4(30.2)$ & $60.5(37.6)$ \\
\hline Physical activity < 34.3 METs (\%) & 33.1 & 33.5 \\
\hline Physical activity 34.3-57.8 METs (\%) & 33.0 & 32.1 \\
\hline Physical activity > 57.8 METs (\%) & 33.9 & 34.9 \\
\hline Current smoker (\%) & 14.5 & 11.8 \\
\hline Ex-smoker (\%) & 31.4 & 34.9 \\
\hline Never smoker (\%) & 54.1 & 53.3 \\
\hline Ever MHT use (\%) & 43.2 & 55.5 \\
\hline \multicolumn{3}{|l|}{ Static variables } \\
\hline Education level (High-school / University $(>=\mathrm{BAC}+4)$ ) & $65.1 / 34.9$ & \\
\hline Parity (number of pregnancies) & 2.1 & \\
\hline Natural menopause (\%) & 88.0 & \\
\hline Family history CVD (\%) & 30.6 & \\
\hline Non-O blood group (\%) & 56.6 & \\
\hline
\end{tabular}

*assessed in 2004

2488 participants died between 1992 and 2002

a reduced risk of primary VTE $\left(\mathrm{HR}_{\mathrm{dys}}=0.68(0.52\right.$ : $0.89)$ ), and DVT ( $\mathrm{HR}_{\mathrm{dys}}=0.83$ (0.71: 0.97)), after adjustment for BMI. When the dyslipidaemia and statin treatment variables were combined, 'treated dyslipidaemia' was not significantly associated with a reduced risk of primary VTE (HR treated dys $=0.98$ (0.84: 1.16), not tabulated), compared to participants reporting no dyslipidaemia or statin reimbursement. This was also observed for DVT $\left(\mathrm{HR}_{\text {treated dys }}=0.85\right.$ (0.68: 1.05), not tabulated). Diabetes was associated with a reduced risk of secondary VTE $\left(\mathrm{HR}_{\text {diab }}=0.66(0.44: 0.98)\right)$, but only 25 cases occurred among participants with diabetes, and was not significant after Bonferroni correction.

Results were similar when controlling for incident coronary disease, stroke, and cancer (supplementary Table 1). Association between hypertension and PE were consistent,
$\left(\mathrm{HR}_{\text {hta }}=1.20\right.$ (1.00: 1.45)), and similarly for dyslipidaemia and DVT (HR dys $=0.83$ (0.71: 0.97)) and primary VTE $\left(\mathrm{HR}_{\mathrm{dys}}=0.68\right.$ (0.52: 0.89)). Similarly, results were comparable when considering only cases that were validated by imaging procedures (Table 3), although the effect estimate confidence intervals were wider due to the reduced number of cases. Association between hypertension and PE were borderline, but of the same magnitude $\left(\mathrm{HR}_{\mathrm{hta}}=1.22\right.$ (0.95: 1.56)), and similarly for dyslipidaemia and DVT $\left(\mathrm{HR}_{\mathrm{dys}}=0.86\right.$ (0.71: 1.04)). Associations between dyslipidaemia and primary VTE were consistent $\left(\mathrm{HR}_{\mathrm{dys}}=0.74\right.$ (0.56: 0.99)), as were associations between physical activity and primary VTE $\left(\mathrm{HR}_{\mathrm{T} 3}=0.70(0.54: 0.90)\right)$. When mutually adjusting for comorbid conditions at baseline, results were similar to those presented in the main analysis (data not tabulated). 


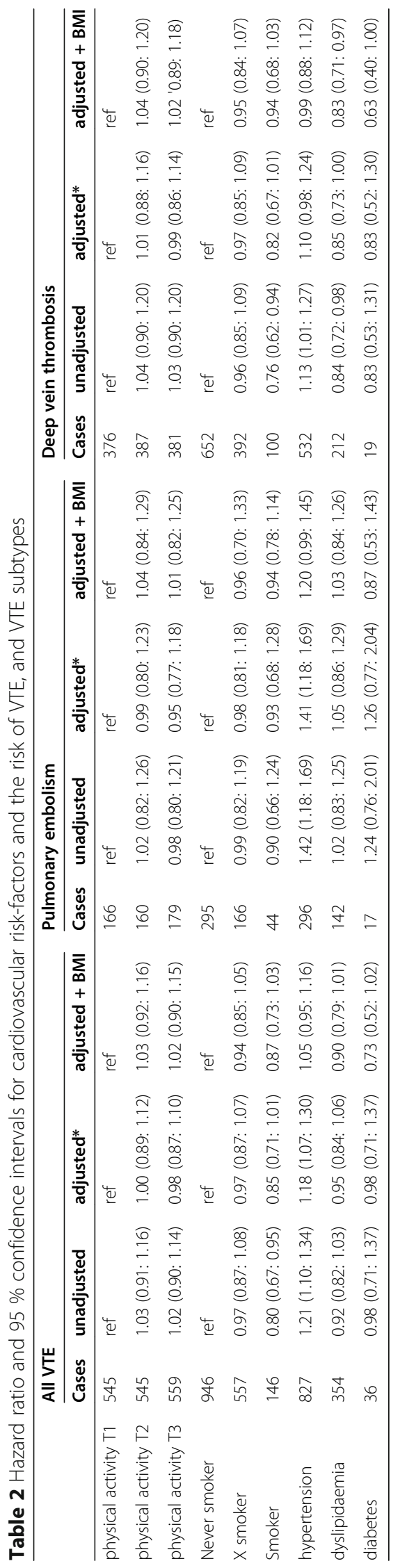




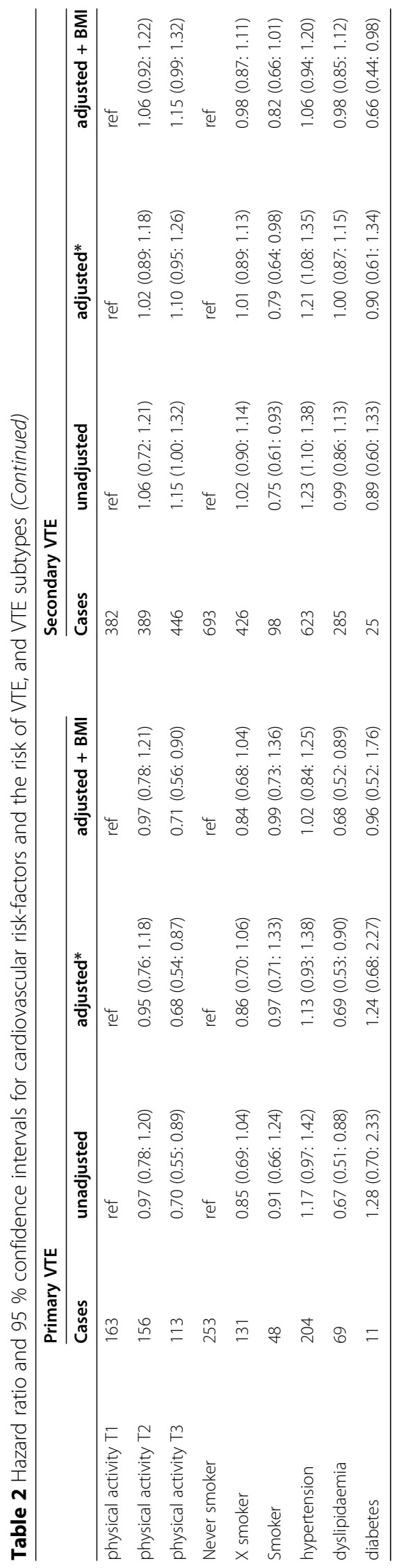


Table 3 Sensitivity analysis including cases occurring until 2005 which were strictly validated via mailing

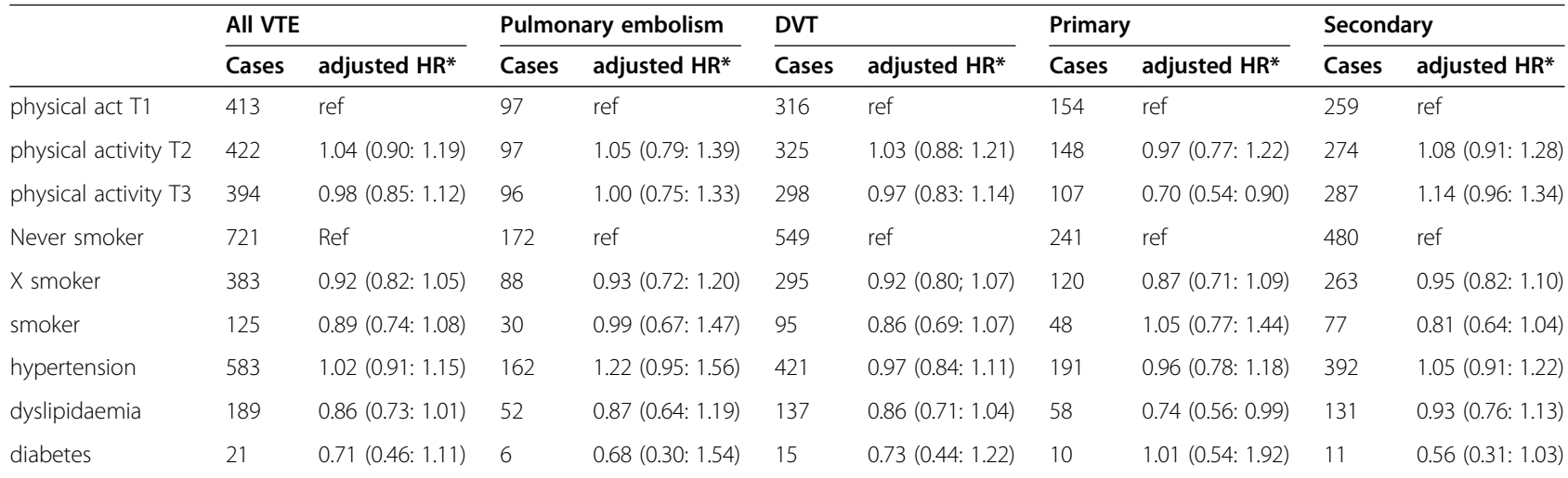

*adjusted on education level, statin use, menopause, MHT use, parity, type of menopause, family history of CVD and BMI

Associations between hypertension, dyslipidaemia and VTE differed slightly depending on ABO blood group (Table 4). Hypertension was associated with a higher risk of primary VTE amongst $\mathrm{O}$-group participants $\left(\mathrm{HR}_{\mathrm{HTA}}=\right.$ 1.56 (1.07: 2.27)), and a non-significant increased risk of $\mathrm{PE}\left(\mathrm{HR}_{\mathrm{HTA}}=1.21(0.88: 1.68)\right)$. Dyslipidaemia was associated with a reduced risk of VTE amongst $\mathrm{O}$-group participants $\left(\mathrm{HR}_{\mathrm{DYS}}=0.78\right.$ (0.63: 0.98), Table 3$)$, with similar associations for all types of VTE (Table 4), but these associations were not consistent when considering the 'treated dyslipidaemia' variable, and showed no significant deviation from $H R=1$ (not tabulated).

\section{Discussion}

In this large cohort of women, hypertension, dyslipidaemia, and diabetes were not associated with the risk of all-VTE after adjustment for BMI. We observed negative associations between physical activity and the risk of primary VTE, and potential negative associations between dyslipidaemia and primary VTE.

In this study, no evidence for associations between cardiovascular risk-factors and all-VTE was observed, or disappeared after adjustment for BMI. BMI has been identified as a major risk-factor for VTE in multiple previous studies [12, 23-26], and confounded associations assessed in this study. BMI possibly explains previous positive associations between cardiovascular risk-factors and VTE in studies that were not adjusted for BMI. Studies of genetic variations using Mendelian randomisation provide evidence of the causal link between increased weight and VTE [27, 28]. These results suggest that people with metabolic conditions such as hypertension, diabetes and dyslipidaemia may not be at increased risk of VTE, given that they have a BMI within the healthy range.

VTE commonly presents with comorbid conditions such as endothelial dysfunction [29], and signs of atherosclerosis [30]. Prospective studies into risk factors for VTE provided conflicting results. A 2017 meta-analysis of prospective studies identified an inverse association between systolic blood pressure and VTE risk [11]. This inverse association was strongest in the highest range of systolic pressure $(140-200 \mathrm{mmHg})$, but considering participants who may be approaching hypertensive crises ( $>180 \mathrm{mmHg}$ ) may not represent the general population, and could be affected by bias due to unmeasured confounding from hypertension medications, lifestyle changes to reverse hypertension, diagnosis biases, or specific surveillance

Table 4 Hazard ratio and 95\% confidence intervals for cardiovascular risk factors and specific VTE type in strata of blood ABO group for metabolic conditions

\begin{tabular}{|c|c|c|c|c|c|c|}
\hline & p-interaction* & All VTE & Pulmonary Embolism & Deep vein thrombosis & Primary & Secondary \\
\hline \multicolumn{7}{|l|}{ Group O } \\
\hline hypertension & 0.01 & 1.14 (0.95: 1.38) & 1.21 (0.88: 1.68) & 1.10 (0.88: 1.39) & 1.56 (1.07: 2.27) & $1.03(0.83: 1.28)$ \\
\hline dyslipidaemia & 0.78 & 0.70 (0.58: 0.85) & 1.10 (0.78: 1.53) & 0.60 (0.44: 0.83) & 0.67 (0.42: 1.09) & $0.82(0.64: 1.06)$ \\
\hline diabetes & 0.82 & 0.68 (0.36: 1.29) & $0.55(0.20: 1.50)$ & 0.79 (0.35: 1.80) & $1.31(0.47: 3.66)$ & $0.51(0.23: 1.17)$ \\
\hline \multicolumn{7}{|l|}{ Group non-O } \\
\hline hypertension & - & 0.97 (0.85: 1.11) & $1.05(0.82: 1.36)$ & 0.95 (0.81: 1.10) & 0.78 (0.60: 1.01) & 1.05 (0.90: 1.23) \\
\hline dyslipidaemia & - & 0.78 (0.69: 0.88) & 0.78 (0.63: 0.97) & 0.78 (0.67: 0.90) & 0.63 (0.48: 0.83) & 0.83 (0.72: 0.95) \\
\hline diabetes & - & $0.78(0.51: 1.18)$ & 1.19 (0.66: 2.15) & $0.56(0.31: 1.01)$ & 1.02 (0.47: 2.19) & 0.71 (0.43: 1.16) \\
\hline
\end{tabular}

* interaction with all-VTE

* adjusted on education level, statin use, menopause, MHT use, parity, type of menopause, family history of CVD and BMI 
for cardiovascular conditions. Another meta-analysis in 2016 of prospective and case-control studies has indicated that hypertension is associated with an increased risk for VTE compared to non-hypertensive subjects [31]. In the Nurses' Health Study [32], hypertension was identified as a risk factor for VTE, with a relative risk of 1.9; however, hypertension was not identified as risk factor in the Framingham Heart Study [33]. Our study of French women observed no associations between hypertension and allVTE, but a weak association between hypertension and PE was identified. It is possible that these results could be explained by uncontrolled confounding from conditions such as pulmonary disease (or other respiratory conditions), which could be associated with both hypertension [34], and the risk of PE [35]. Similarly, isolated PE has been associated with a higher risk of arterial thrombotic events [36], which could possibly be explained by underlying hypertension among people with PE as reported in our results.

Previous studies have mostly shown that neither diabetes nor dyslipidaemia are associated with the risk of VTE [24, 26, 37]. The LITE study identified a slightly increased risk of VTE amongst participants with diabetes $(\mathrm{HR}=1.5$ (95\% CI: 1.0-2.1)) [25]. One meta-analysis [38] of 19 prospective cohort and case control studies found a weak positive, but non-significant association between diabetes and VTE risk ( $\mathrm{HR}=1.10$ (95\% CI: 0.94-1.29)). The authors conclude that diabetes is unlikely to play a major role in VTE development, which our study supports. We were however limited by the number of cases which occurred amongst diabetic women, and the relatively low number of diabetic women in the cohort.

We observed a weak association between dyslipidaemia and the risk of primary VTE. Despite controlling for statins, it is possible that this relationship could be confounded by treatment for dyslipidaemia other than statins, or for behavioural changes provoked by a diagnosis of dyslipidaemia. These associations were not consistent when considering self-reported dyslipidaemia cross-referenced with statin reimbursement. Interestingly Wattanakit et al. [12] also observed a weak negative association between high concentrations of LDL-C, and all VTE (HR $L D L>160=0.73$ (0.54: 0.98)), and the UK biobank study observed inverse associations between apolipoprotein B, lipoprotein(a), and the risk of VTE [9]. Further research should be conducted to further understand these observations, which could possibly be resulting from bias after adjusting on an intermediate variable during follow-up, or due to time-varying confounding which may not be appropriately controlled for under the modelling strategy used [39]. It is unclear whether any independent protective effect from statins exists, despite Rovustatin having been shown to reduce the likelihood of VTE in a large RCT [40]. Statins are theorised to reduce the risk of VTE through mechanisms independent to the lowering of LDL-C [41], such as increased anticoagulant activity. Elevated or oxidised low density lipoprotein (LDL) can promote thrombin formation [42], thus an imbalance in lipids may result in a hypercoagulative state.

In this study, we observed no association between smoking, and the risk of VTE. This is in opposition to previous studies $[43,44]$ including the large UK biobank study that observed convincing associations between smoking and the risk of VTE [9]. A previous metaanalysis [7] of 32 observational studies has shown that smoking is associated with an increased risk of VTE, with a risk ratio of 1.19 as well as linear responses from pack-years and cigarettes per day. We were unable to reproduce this observation perhaps due to the low number of smokers in this cohort, and that many participants quit smoking during follow-up. It is also possible that the effect of smoking could be mediated, or masked, by a lower BMI among smokers.

Total physical activity as estimated by METS was not associated with the overall risk of VTE, although the highest levels of physical activity were associated with a reduced risk of primary VTE. Previous prospective studies have shown similar results regarding all VTE, and data from the Nurses' Health Study [45] have shown that time spent inactive (but not total physical activity) is associated with an increased risk of pulmonary embolism. Physical activity could reduce the risk of VTE by improving circulation and the quality of blood-vessels, and lowering the likelihood of blood stagnation in the lower extremities which can lead to deep vein thrombosis. It is possible that time spent stationary could be a more important predictor of VTE than total physical activity.

Regarding ABO group, associations between hypertension and primary VTE were higher within the $\mathrm{O}$ group. The AB blood group is associated with an increased risk for VTE, through increased von Willebrand factor (VWF) [46]. Hypertension is also associated with increased VWF concentrations [47], and the O-group is associated with higher rates of hypertension [19]. It is possible that patients with $\mathrm{O}$ blood group and hypertension have similar VWF levels as patients with $A B$ blood group and no hypertension, and that further increases in VWF in $\mathrm{AB} /$ hypertensive cases are limited. It is less clear why dyslipidaemia appeared associated with a reduced risk only amongst $\mathrm{O}$-group participants, and these observations may have occurred by chance as the $p$-values were non-significant.

\section{Strengths and limitations}

This study has a number of strengths, notably a long follow-up, large number of participants and cases, control for a large set of potential confounders, detailed 
reporting on the type of VTE, and a validation procedure used for all cases. Exposures of metabolic conditions were verified against specific treatment reimbursements. Regarding hypertension and diabetes, self-reported hypertension showed strong correlation with reimbursements for blood-pressure lowering medications, and diabetes cases were validated via a specific questionnaire. Measured blood pressure values, and cholesterol values were not available for the majority of study participants, thus it was not possible to determine if there is some non-linear relationship between blood-pressure levels/ serum cholesterol and the risk of VTE. The dichotomisation of these variables should be considered a major limitation of the current approach.

As later VTE cases were based on self-reports verified by drug reimbursement, it is possible that a number of cases were misdiagnosed, or that cases were missed. Regarding DVT, it is possible that misclassification between superficial and deep thrombosis could occur. Baseline dyslipidaemia cases were based on self-reports, but later cases were verified by treatment reimbursements in secondary analysis. Smoking data was based on self-reports, and included a low number of current smokers, resulting in a lower statistical power to investigate associations among smokers. Similarly, physical activity data was based on self-report and may be subject to error. However, these data were assessed prior to the VTE event, and any error should be independent of the event.

A major strength is the consideration of risk-factors as time dependent variables, as a large number of participants developed hypertension and dyslipidaemia during follow up. However, this method can also introduce bias, through the inclusion of time-varying covariates or potential mediators in the model $[39,48]$. Future studies should address this limitation using g-methods [49], which can take into account time-varying confounding without potentially introducing bias from time-varying covariates. Due to this possibility, models considering only baseline data were considered in sensitivity analysis, and showed no major differences. Limitations include the lack of data on medications at study baseline, and the fact that later cases of VTE were validated only via drug reimbursements, and not on information from imaging procedures. Reassuringly, we did observe similar results when only considering cases strictly validated via specific mailings to medical practitioners. The E3N cohort is rather homogenous, and the majority of participants are at a low-risk of non-communicable diseases such as VTE, and cardiovascular disease, thus it is unclear how these observations may translate to higherrisk populations.

As treatments for hypertension, diabetes, and dyslipidaemia are commonly long-term [50], we are confident that these exposures are true representations of these metabolic conditions. Although these conditions are potentially reversible with weight loss and changes in the diet, this would be hard to verify. It is possible that some residual confounding from other lifestyle factors could drive some of the associations observed, especially for the negative associations between dyslipidaemia and primary VTE. The modelling approach chosen, i.e. not mutually adjusting for all considered risk-factors reduces the likelihood of including mediators as in the model, which could introduce collider bias (for example baseline physical activity may influence the future risk of hypertension). Unmeasured confounding is another major concern. For example, certain auto-immune conditions such as rheumatoid arteritis are associated with hypertension [51], and with the risk of VTE [52]. Assuming that these types of conditions can cause hypertension, then associations between hypertension and VTE may be positively biased, which could potentially explain the observations between hypertension and PA. However as these conditions are relatively rare in the general population, we believe that this is a low risk of bias. Similarly, medications that can provoke VTE were unadjusted for, but unless they are causally related to the considered exposures and the thrombotic events, then they should not majorly bias the results. The lack of control for factors such as these is a common limitation in many previous cohort studies of VTE $[12,25]$.

\section{Conclusion}

Altogether these results suggest that the common riskfactors for CVD are not risk factors for VTE. Regular physical activity may reduce the risk of primary VTE. We confirm previous observations linking dyslipidaemia to a reduced risk of VTE, which should be investigated in future studies. People with metabolic conditions, but with a healthy BMI may not be at higher risk of VTE.

\section{Abbreviations \\ CVD: Cardiovascular disease; VTE: venous thromboembolism; PE: pulmonary embolism; DVT: deep vein thrombosis; E3N: Etude Epidémiologique auprès de femmes de la Mutuelle Générale de l'Education Nationale; \\ MGEN: Mutuelle Générale de I'Education Nationale; MHT: menopausal hormone therapy; BMl: body mass index}

\section{Supplementary Information}

The online version contains supplementary material available at https://doi. org/10.1186/s12959-021-00310-w.

\section{Additional file 1.}

Acknowledgements

We gratefully acknowledge the contribution of all the participants in the $\mathrm{E} 3 \mathrm{~N}$ study for their diligence and their answers. The authors have no conflicts of interest to declare. 


\section{Authors' contributions}

C J MacDonald - study design, conducting research, writing. AL Madika conducting research, writing, approval of final draft. M Lajous - study design, conducting research, writing, approval of final draft. M Canonico - study design, approval of final draft. A Fournier - study design, approval of final draft. MC Boutron-Ruault - supervision, approval of final draft.

\section{Funding}

The E3N cohort is being carried out with the financial support of the "Mutuelle Générale de l'Education Nationale" (MGEN); European Community; French League against Cancer (LNCC); Gustave Roussy Institute (IGR); French Institute of Health and Medical Research (INSERM). This present study was also supported by the French Research Agency (Agence Nationale de la Recherche) via an "Investissement d'Avenir" grant (investment for the future grant, ANR-10-COHO-0006).

CJM is supported by funding from the Federation Française de Cardiologie. The funders had no role in study design, data collection and analysis, decision to publish, or preparation of the manuscript.

\section{Availability of data and materials}

The datasets generated and/or analysed during the current study are not publicly available due to data sharing protocols but are available from the corresponding author on reasonable request.

\section{Declarations}

\section{Ethics approval and consent to participate}

participants signed an informed consent form in accordance to the French National Commission for Data Protection and Privacy.

\section{Consent for publication}

Not applicable.

\section{Competing interests}

The authors have no conflicts of interest to declare.

\section{Author details}

'INSERM (Institut National de la Santé et de la Recherche Médicale) U1018, Center for Research in Epidemiology and Population Health (CESP), Institut Gustave Roussy, Villejuif, France. ${ }^{2}$ Université Paris-Saclay, Université Paris-Sud, Villejuif, France. ${ }^{3}$ Université de Lille, CHU Lille, EA 2694 - Santé publique : épidémiologie et qualité des soins, F-59000 Lille, France. ${ }^{4}$ Center for Research on Population Health, INSP (Instituto Nacional de Salud Pública), Cuernavaca, Mexico. ${ }^{5}$ Department of Global Health and Population, Harvard T.H. Chan School of Public Health, Boston, MA, USA.

Received: 26 May 2021 Accepted: 5 August 2021

Published online: 21 August 2021

\section{References}

1. Cohen AT, Agnelli G, Anderson FA, Arcelus JI, Bergqvist D, Brecht JG, Greer IA, Heit JA, Hutchinson JL, Kakkar AK, Mottier D, Oger E, Samama M-M, Spannagl M, VTE Impact Assessment Group in Europe (VITAE). Venous thromboembolism (VTE) in Europe. The number of VTE events and associated morbidity and mortality. Thromb Haemost. 2007;98:756-764.

2. Raskob GE, Angchaisuksiri P, Blanco AN, Buller H, Gallus A, Hunt BJ, et al. Thrombosis: a major contributor to global disease burden. Arterioscler Thromb Vasc Biol. 2014;34(11):2363-71. https://doi.org/10.1161/ATVBA HA.114.304488.

3. Lijfering WM, Rosendaal FR, Cannegieter SC. Risk factors for venous thrombosis - current understanding from an epidemiological point of view: review. Br J Haematol. 2010;149(6):824-33. https://doi.org/10.1111/j.13 65-2141.2010.08206.x.

4. Ay C, Pabinger I, Cohen AT. Cancer-associated venous thromboembolism: burden, mechanisms, and management. Thromb Haemost. 2017;117(2):21930. https://doi.org/10.1160/TH16-08-0615.

5. Heit JA. Epidemiology of venous thromboembolism. Nat Rev Cardiol. 2015; 12(8):464-74. https://doi.org/10.1038/nrcardio.2015.83.

6. Ageno W, Becattini C, Brighton T, Selby R, Kamphuisen PW. Cardiovascular risk factors and venous thromboembolism: a Meta-analysis. Circulation. 2008;117(1):93-102. https://doi.org/10.1161/CIRCULATIONAHA.107.709204.
7. Cheng Y-J, Liu Z-H, Yao F-J, Zeng W-T, Zheng D-D, Dong YG, et al. Current and Former Smoking and Risk for Venous Thromboembolism: A Systematic Review and Meta-Analysis. PLoS Med. 2013;10:e1001515.

8. Holst AG, Jensen G, Prescott E. Risk factors for venous thromboembolism: results from the Copenhagen City heart study. Circulation. 2010;121(17): 1896-903. https://doi.org/10.1161/CIRCULATIONAHA.109.921460.

9. Gregson J, Kaptoge S, Bolton T, Pennells L, Willeit P, Burgess S, et al. Cardiovascular Risk Factors Associated With Venous Thromboembolism. JAMA Cardiol. 2019;4:163.

10. Zhang Y, Yang Y, Chen W, Liang L, Zhai Z, Guo L, et al. Hypertension associated with venous thromboembolism in patients with newly diagnosed lung cancer. Sci Rep. 2016;6:19603.

11. Mahmoodi BK, Cushman M, Anne Næss I, Allison MA, Bos WJ, Brækkan SK, et al. Association of Traditional Cardiovascular Risk Factors With Venous Thromboembolism: An Individual Participant Data Meta-Analysis of Prospective Studies. Circulation. 2017;135:7-16.

12. Wattanakit K, Lutsey PL, Bell EJ, Gornik H, Cushman M, Heckbert SR, et al. Association between cardiovascular disease risk factors and occurrence of venous thromboembolism. A time-dependent analysis. Thromb Haemost. 2012;108(3):508-15. https://doi.org/10.1160/TH11-10-0726.

13. van Liere MJ, Giubout C, Niravong MY, Goulard H, Corre CL, Hoang LA, et al. E3N, a French cohort study on cancer risk factors. European Journal of Cancer Prevention. 1997;6:473-8.

14. Canonico M, Fournier A, Carcaillon L, Olié V, Plu-Bureau G, Oger E, et al. Postmenopausal hormone therapy and risk of idiopathic venous thromboembolism: results from the E3N cohort study. ATVB. 2010;30(2):3405. https://doi.org/10.1161/ATVBAHA.109.196022.

15. Fagherazzi G, Vilier A, Bonnet F, Lajous M, Balkau B, Boutron-Ruault M-C, et al. Dietary acid load and risk of type 2 diabetes: the E3N-EPIC cohort study. Diabetologia. 2014;57(2):313-20. https://doi.org/10.1007/s00125013-3100-0.

16. Ainsworth BE, Haskell WL, Whitt MC, Irwin ML, Swartz AM, Strath SJ, et al. Compendium of Physical Activities: an update of activity codes and MET intensities. Medicine \& Science in Sports Exercise. 2000;32:S498-516.

17. Tehard B, Liere MJV, Nougué CC, Clavel-Chapelon F. Anthropometric measurements and body Silhouette of women. J Am Diet Assoc. 2002; 102(12):1779-84. https://doi.org/10.1016/50002-8223(02)90381-0.

18. Langman MJS, Foote J, Elwood PC, Ryrie DR. Abo and LEWIS blood-groups and serum-cholesterol. Lancet. 1969;294(7621):607-9. https://doi.org/10.101 6/50140-6736(69)90323-7.

19. Groot HE, Villegas Sierra LE, Said MA, Lipsic E, Karper JC, van der Harst P. Genetically determined $\mathrm{ABO}$ blood group and its associations with health and disease. ATVB. 2020;40(3):830-8. https:/doi.org/10.1161/ATVBAHA.119.313658.

20. Fagherazzi G, Gusto G, Clavel-Chapelon F, Balkau B, Bonnet F. ABO and Rhesus blood groups and risk of type 2 diabetes: evidence from the large E3N cohort study. Diabetologia. 2015;58(3):519-22. https://doi.org/10.1007/ s00125-014-3472-9.

21. Larson NB, Bell EJ, Decker PA, Pike M, Wassel CL, Tsai MY, et al. ABO blood group associations with markers of endothelial dysfunction in the multiethnic study of atherosclerosis. Atherosclerosis. 2016;251:422-9. https://doi. org/10.1016/j.atherosclerosis.2016.05.049.

22. Grambsch PM, Therneau TM. Proportional hazards tests and diagnostics based on weighted residuals. Biometrika. 1994;81(3):515-26. https://doi. org/10.1093/biomet/81.3.515

23. Kabrhel C, Varraso R, Goldhaber SZ, Rimm EB, Camargo CA. Prospective study of BMl and the risk of pulmonary embolism in women. Obesity. 2009; 17(11):2040-6. https://doi.org/10.1038/oby.2009.92.

24. Glynn RJ, Rosner B. Comparison of risk factors for the competing risks of coronary heart disease, stroke, and venous thromboembolism. Am J Epidemiol. 2005;162(10):975-82. https://doi.org/10.1093/aje/kwi309.

25. Tsai AW, Cushman M, Rosamond WD, Heckbert SR, Polak JF, Folsom AR. Cardiovascular risk factors and venous thromboembolism incidence: the longitudinal investigation of thromboembolism etiology. Arch Intern Med. 2002;162(10):1182-9. https://doi.org/10.1001/archinte.162.10.1182.

26. Brækkan SK, Hald EM, Mathiesen EB, Njølstad I, Wilsgaard T, Rosendaal FR, et al. Competing risk of atherosclerotic risk factors for arterial and venous thrombosis in a general population: the Tromsø study. Arterioscler Thromb Vasc Biol. 2012;32(2):487-91. https://doi.org/10.1161/ATVBAHA.111.237545.

27. Klovaite J, Benn M, Nordestgaard BG. Obesity as a causal risk factor for deep venous thrombosis: a Mendelian randomization study. J Intern Med. 2015; 277(5):573-84. https://doi.org/10.1111/joim.12299. 
28. Lindström S, Germain M, Crous-Bou M, Smith EN, Morange P-E, van Hylckama VA, et al. Assessing the causal relationship between obesity and venous thromboembolism through a Mendelian randomization study. Hum Genet. 2017;136(7):897-902. https://doi.org/10.1007/s00439-017-1811-x.

29. Poredos P, Jezovnik MK. Endothelial dysfunction and venous thrombosis. Angiology. 2018;69(7):564-7. https://doi.org/10.1177/0003319717732238.

30. Prandoni P, Bilora F, Marchiori A, Bernardi E, Petrobelli F, Lensing AWA, et al. An association between atherosclerosis and venous thrombosis. N Engl J Med. 2003;348(15):1435-41. https://doi.org/10.1056/NEJMoa022157.

31. Mi Y, Yan S, Lu Y, Liang Y, Li C. Venous thromboembolism has the same risk factors as atherosclerosis: a PRISMA-compliant systemic review and metaanalysis. Medicine. 2016;95(32):e4495. https://doi.org/10.1097/MD. 0000000000004495.

32. Goldhaber SZ, Grodstein F, Stampfer MJ, Manson JE, Colditz GA, Speizer FE, et al. A prospective study of risk factors for pulmonary embolism in women. JAMA. 1997;277(8):642-5. https://doi.org/10.1001/jama.1997.03540320044033.

33. Puurunen MK, Gona PN, Larson MG, Murabito JM, Magnani JW, O'Donnell CJ. Epidemiology of venous thromboembolism in the Framingham heart study. Thromb Res. 2016;145:27-33. https://doi.org/10.1016/j.thromres.2016. 06.033.

34. Kim S-H, Park J-H, Lee J-K, Heo EY, Kim DK, Chung HS. Chronic obstructive pulmonary disease is independently associated with hypertension in men: A survey design analysis using nationwide survey data. Medicine (Baltimore). 2017;96:e6826

35. de Miguel Diez J, Albaladejo-Vicente R, Jiménez-García R, Hernandez-Barrera $V$, Villanueva-Orbaiz R, Carabantes-Alarcon D, et al. The effect of COPD on the incidence and mortality of hospitalized patients with pulmonary embolism: A nationwide population-based study (2016-2018). Eur J Intern Med. 2021;84:18-23.

36. ten Cate V, Eggebrecht L, Schulz A, Panova-Noeva M, Lenz M, Koeck T, et al. Isolated pulmonary embolism is associated with a high risk of arterial thrombotic disease. Chest. 2020;158(1):341-9. https://doi.org/10.1016/j. chest.2020.01.055

37. Quist-Paulsen P, Naess IA, Cannegieter SC, Romundstad PR, Christiansen SC, Rosendaal FR, et al. Arterial cardiovascular risk factors and venous thrombosis: results from a population-based, prospective study (the HUNT 2). Haematologica. 2010;95(1):119-25. https://doi.org/10.3324/haematol.2009. 011866.

38. Bell EJ, Folsom AR, Lutsey PL, Selvin E, Zakai NA, Cushman M, et al. Diabetes mellitus and venous thromboembolism: a systematic review and metaanalysis. Diabetes Res Clin Pract. 2016;111:10-8. https://doi.org/10.1016/j.dia bres.2015.10.019.

39. Doosti-Irani A, Mansournia MA, Collins G. Use of G-methods for handling time-varying confounding in observational research. Lancet Glob Health 2019;7(1):e35. https://doi.org/10.1016/S2214-109X(18)30471-6.

40. Glynn RJ, Danielson E, Fonseca FAH, Genest J, Gotto AM, Kastelein JJP, et al. A randomized trial of rosuvastatin in the prevention of venous thromboembolism. N Engl J Med. 2009;360(18):1851-61. https://doi.org/10.1 056/NEJMoa0900241

41. Zaccardi F, Kunutsor SK, Seidu S, Davies MJ, Khunti K. Is the lower risk of venous thromboembolism with statins related to low-density-lipoprotein reduction? A network meta-analysis and meta-regression of randomised controlled trials. Atherosclerosis. 2018;271:223-31. https://doi.org/10.1016/j.a therosclerosis.2018.02.035.

42. Griffin J, Fernández J, Deguchi H. Plasma Lipoproteins. Hemostasis and Thrombosis Thromb Haemost. 2001;86(1):386-94

43. Lutsey PL, Virnig BA, Durham SB, Steffen LM, Hirsch AT, Jacobs DR, et al. Correlates and consequences of venous thromboembolism: the lowa Women's health study. Am J Public Health. 2010;100(8):1506-13. https://doi. org/10.2105/AJPH.2008.157776.

44. Enga KF, Braekkan SK, Hansen-Krone IJ, le Cessie S, Rosendaal FR, Hansen JB. Cigarette smoking and the risk of venous thromboembolism: the Troms $\varnothing$ study. J Thromb Haemost. 2012;10(10):2068-74. https://doi.org/10.1111/j.153 8-7836.2012.04880.x.

45. Kabrhel C, Varraso R, Goldhaber SZ, Rimm E, Camargo CA. Physical inactivity and idiopathic pulmonary embolism in women: prospective study. BMJ. 2011;343(jul04 1):d3867. https://doi.org/10.1136/bmj.d3867.

46. Brill A, Fuchs TA, Chauhan AK, Yang JJ, De Meyer SF, Köllnberger M, et al. von Willebrand factor-mediated platelet adhesion is critical for deep vein thrombosis in mouse models. Blood. 2011;117(4):1400-7. https://doi.org/1 0.1182/blood-2010-05-287623.
47. van den Born B-JH, van der Hoeven NV, Groot E, Lenting PJ, Meijers JCM, Levi $M$, et al. Association between thrombotic microangiopathy and reduced ADAMTS13 activity in malignant hypertension. Hypertension. 2008; 51(4):862-6. https://doi.org/10.1161/HYPERTENSIONAHA.107.103127.

48. Robins JM. Causal models for estimating the effects of weight gain on mortality. Int J Obes. 2008;32(Suppl 3):S15-41. https://doi.org/10.1038/ijo.2 008.83.

49. Naimi Al, Cole SR, Kennedy EH. An introduction to g methods. Int J Epidemiol. 2017;46(2):756-62. https://doi.org/10.1093/ije/dyw323.

50. Cubeddu LX, Seamon MJ. Statin withdrawal: clinical implications and molecular mechanisms. Pharmacotherapy. 2006;26(9):1288-96. https://doi. org/10.1592/phco.26.9.1288.

51. Panoulas VF, Metsios GS, Pace AV, John H, Treharne GJ, Banks MJ, et al. Hypertension in rheumatoid arthritis. Rheumatology. 2008;47(9):1286-98. https://doi.org/10.1093/rheumatology/ken159.

52. Li L, Lu N, Avina-Galindo AM, Zheng Y, Lacaille D, Esdaile JM, et al. The risk and trend of pulmonary embolism and deep vein thrombosis in rheumatoid arthritis: a general population-based study. Rheumatology (Oxford). 2021;60:188-95.

\section{Publisher's Note}

Springer Nature remains neutral with regard to jurisdictional claims in published maps and institutional affiliations.
Ready to submit your research? Choose BMC and benefit from:

- fast, convenient online submission

- thorough peer review by experienced researchers in your field

- rapid publication on acceptance

- support for research data, including large and complex data types

- gold Open Access which fosters wider collaboration and increased citations

- maximum visibility for your research: over $100 \mathrm{M}$ website views per year

At $\mathrm{BMC}$, research is always in progress.

Learn more biomedcentral.com/submissions 